Article

\title{
Optimal Design of the Vertical Earthing with Electrodes Arranged in Line
}

\author{
Sorin Gheorghe Pavel ${ }^{1}$, Virgil Maier ${ }^{1}$, Claudiu Ciorca ${ }^{1}$, Horia Gheorghe Beleiu ${ }^{1, *}$ \\ and Iulian Birou ${ }^{2}$ \\ 1 Department of Electrical Power System and Management, Faculty of Electrical Engineering, \\ Technical University of Cluj-Napoca, 28 Memorandumului Street, 400114 Cluj-Napoca, Romania; \\ sorin.pavel@enm.utcluj.ro (S.G.P.); virgil.maier@enm.utcluj.ro (V.M.); ciorcaclaudiu@gmail.com (C.C.) \\ 2 Department of Electric Machines and Drives, Faculty of Electrical Engineering, Technical University of \\ Cluj-Napoca, 28 Memorandumului Street, 400114 Cluj-Napoca, Romania; iulian.birou@emd.utcluj.ro \\ * Correspondence: horia.beleiu@enm.utcluj.ro
}

Received: 9 January 2020; Accepted: 7 February 2020; Published: 10 February 2020

check for updates

\begin{abstract}
The design methods of earthing from standards recommend the choice of electrode lengths and propose that the distances between electrodes to be 1-3 times larger than their length. The number of electrodes is determined from the condition of achieving the design earth resistance, while the design ends with the choice of one of the variants. This paper presents the methodology for calculating the earthing system with cylindrical, vertical electrodes arranged in a line. The main variables are the length and the number of earth electrodes, as well as the distance between adjacent ones. Firstly, a set of technologically advantageous values for the earth electrode length is established (e.g., 10 values). For each value of the electrode length and different numbers of electrodes (e.g., 11 values), the distance between adjacent electrodes is determined (e.g., for 110 cases), which leads to the design value resistance. Finally, optimal solutions are identified based on the five optimal applied criteria. The proposed optimal criteria for earthing design are the footprint area, the total earthing volume, the total dispersion surface, the total metal mass, and the investment costs. Comparing the optimal solutions with other technically possible solutions clearly highlights substantial savings concerning space, material, and cost.
\end{abstract}

Keywords: resistance to earth; earthing system design; earthing electrodes; optimal criteria; power system security

\section{Introduction}

From the outset, it is emphasized that all computational relations included in the mathematical model of the system of earthing (EG) used in the present research are based on current international standards [1-8]. They have been used by specialists for over 40 years and are verified in practice. The calculation methods from the normative documents have been resumed and exemplified in many specialized manuals [9-13]. It is necessary to specify that the proposed developments, simplifications, and refinements for the updated design of the EG [14-17] should not be interpreted as a reconsideration of their calculation methodology.

Until the optimum criteria appeared, the EG designers first selected an electrode length suitable for the respective soil [1,3,5-8], selected several values for the distance between adjacent electrodes, and then determined the number of electrodes to achieve the designed earth resistance. Usually, the distance between adjacent electrodes was chosen 1-3 times greater than the length of the electrodes, as indicated in the standard [5,6], in order to obtain a higher value of the coefficient of use. From 
several calculated variants, the designer selected the most convenient one (e.g., a lower number of electrodes, lower earth resistance).

For example, the standard [1] explicitly recommends the following: "Pipes may be of cast iron of not less than $100 \mathrm{~mm}$ diameter, $2.5 \mathrm{~m}$ to $3 \mathrm{~m}$ long and $13 \mathrm{~mm}$ thick". Examples, when given, are conducted at most until the design value resistance is obtained $[1,5,6,11,12]$, and optimum selection criteria are not indicated.

Previous publications concerning earthing optimum design refer to structural modifications of the earth grids or systems "in order to equalize the leakage current distribution and the potential of ground surface" [18] or to minimize the shielding effect [19]. These contributions do not apply optimal criteria to the calculation of the earthing system itself. In the absence of optimal criteria, each earthing system designer has proposed solutions to achieve the designed value resistance to earth. The evaluation of the proposed solution was also made according to the value of the coefficient of use, sufficiently large when the distance between the electrodes is 1-3 times greater than the length of the earth electrodes. The optimal criteria proposed and applied clearly show that there are solutions that minimize the surface or volume occupied by the earthing system, the amount of metal used, or the cost of the earthing system.

Summarizing the achievements of the previous research on the application of optimum criteria in the design of EG [14-17], the following important steps can be mentioned:

- Defining five optimal criteria as follows: the footprint area (noted $A_{P}$ ), the EG total volume $\left(V_{P}\right)$, the total dispersion surface $\left(A_{D}\right)$, the conducting materials mass $\left(M_{P}\right)$, and the investment costs $\left(\mathrm{I}_{\mathrm{P}}\right)$.

- Identifying an analytical expression for the function $\mathrm{f}\left(\mathrm{n}_{\mathrm{e}}\right)$, which introduces the dependence of the coefficient of use $u_{p}$ versus the number of the electrodes $n_{e}$, given in a tabular form in [5], and for which the following analytical expression was determined in [15]:

$$
\mathrm{f}\left(\mathrm{n}_{\mathrm{e}}\right)=1.45 \cdot \lg \mathrm{n}_{\mathrm{e}}+0.1 .
$$

- From the eight characteristic variables of the earthing system with vertical electrodes (VEG), the length and number of electrodes are considered independent variables, and the distance between adjacent electrodes is considered as an intrinsic variable, determined by the condition of the design value resistance.

- Creating an Excel program, which allows determining the distance between adjacent electrodes for all combinations of lengths and numbers of electrodes, achieving the design value resistance.

- Within the same program, the five optimal criteria are applied to the same combinations of lengths-numbers-distances between electrodes to highlight the optimal (minimal) solutions.

- The use of optimal criteria, mentioned above, in the VEG dimensioning with electrodes arranged in a rectangle (VEGR) favored the improvement of the calculation methodology, the achievement of the variables importance hierarchy, and emphasized distinct areas of minimum values.

Realizing an earthing system, with the application of the proposed optimum criteria should follow the next steps: analyzing the offer of earthing components; measuring the resistivity of the soil at several points of the space designated to the earthing system; making calculations and choosing the optimal solution; measuring the resistance to earth of one electrode, at several points of the space where the earthing system will be located, determining the average resistivity of the soil and recalculating the characteristic data for the optimal solution; realizing the earthing system; measuring the total resistance to earth and applying the final, practical corrections. 


\section{Methodological Aspects}

\subsection{Basic Sizes}

The earthing components of a VEG with electrodes arranged in line (VEGL), as well as the main characteristic dimensions, are shown in Figure 1. Only two vertical adjacent electrodes (rod or pipe, 1) are represented (Figure 1a), tied at their top by a horizontal strip (2). The limit of the footprint area on the earth (4) is considered on both sides of the horizontal strip, at a distance equal to half of the distance between two adjacent electrodes (Figure 1b).

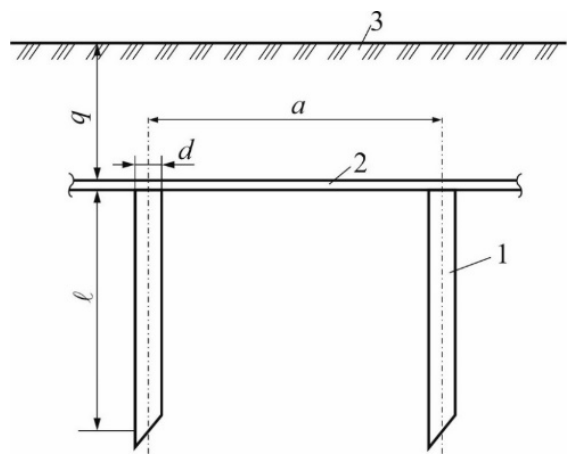

(a)

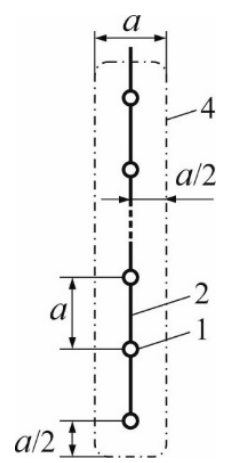

(b)

Figure 1. Multiple earthing system with vertical electrodes (VEG) with vertical electrodes placed after a straight line: (a) partial section, with the main characteristic dimensions; (b) footprint; 1 -electrode; 2-connecting conductor; 3 - the soil; 4 -footprint contour on the ground.

In a synthetic view, the following 8 physical sizes can be considered as characteristic for VEGL:

$$
\left\{\ell, \mathrm{a}, \mathrm{d}, \rho_{\mathrm{p}}, \mathrm{q}, \mathrm{g}, \mathrm{R}_{\mathrm{Pn}}, \mathrm{n}_{\mathrm{e}}\right\},
$$

where $\ell$ is the length of the electrodes, a-the distance between adjacent electrodes, $\mathrm{d}$ - the external diameter of the cylindrical electrodes, $\rho_{\mathrm{p}}$-the resistivity of the soil, assumed uniform, $\mathrm{q}$ - the burial depth of the electrode's upper end, g-the thickness of the pipe wall from which the electrode is realized, $R_{P n}$-the design value resistance and $n_{e}$-the number of electrodes.

Concerning these sizes, the following aspects were highlighted [12]:

- In all practical cases, the variables $\left\{\rho_{p}, q, R_{P n}\right\}$ have determined or imposed values. Thus, the resistivity of the soil $\rho_{\mathrm{p}}$ is experimentally determined by measurements on the soil where the VEGL is to be made. The burial depth, $q$, is imposed by the maximum freezing depth, according to the geographical position of the objective, $\mathrm{q} \in\{0.8-0.9\} \mathrm{m}$ (in Romania and other European countries); $R_{P n} \in\{1,4,5,10\} \Omega$, depending on the VEGL's concrete destination [1,3-5] when there is no natural earthing system. When there is a natural earthing system, the design value resistance will be calculated so that the resistance to earth of combined systems has one of the above values.

- The wall thickness, $g$, of the pipe electrode has a reduced influence on the VEGL resistance to earth, with a recommended value of $g \geq 3.5 \mathrm{~mm}$ for a longer lifetime of the earthing system.

- The electrode's number, which can only be a natural number, $n_{e} \in\{1,2,3, \ldots\}$. follows:

In the present study, the classification of the basic sizes that intervene in the VEGL design is as

- The sizes $\ell$ and $\mathrm{n}_{\mathrm{e}}$ are considered as independent variables, with the ranges of interest values $\ell \in[0.5-4] \mathrm{m}$ and $\mathrm{n}_{\mathrm{e}} \in\{1,2,3, \ldots\}$, increasing the electrodes' numbers up to the limits of the technical solution. 
- The variable a is considered an intrinsic one because its value is determined by the mathematical model based on the other sizes. The lower technical limit is a $\approx 0.2 \mathrm{~m}$.

- The sizes $\left\{d, \rho_{\mathrm{p}}, \mathrm{q}, \mathrm{g}, \mathrm{R}_{\mathrm{Pn}}\right\}$ are considered as parameters that justifiably change from one case to another.

\subsection{Calculation Methodology for VEG with Linearly Placed Electrodes}

The VEGL mathematical model adopted in the present research is the standardized one $[1,3,5,8]$, and, as stated above, no significant changes are envisaged. Next, the main sizing stages of VEGL are briefly reproduced, the chosen form of equations being in accordance with normative documents $[3,5]$.

If the calculation variables $\left\{\mathrm{d}, \ell, \mathrm{q}, \rho_{\mathrm{p}}\right\}$ are known, the resistance to earth $\mathrm{r}_{\mathrm{pv}}$ of one vertical electrode (road or pipe) is calculated with the relation

$$
\mathrm{r}_{\mathrm{p} v}=\frac{0.366 \cdot \rho_{\mathrm{p}}}{\ell} \cdot \lg \left[\frac{2}{\mathrm{~d} / \ell} \cdot \sqrt{1+\frac{1}{2(\mathrm{q} / \ell)+0.5}}\right]
$$

which represents the basis of a calculation nomogram [14]. Examining the respective nomogram offers the possibilities to assess the character of the dependences of the earth electrode resistance on the involved variables, and to evaluate the magnitude of the variations determined by the independent variables.

The combined resistance to earth $R_{P e}$ of all vertical electrodes, realized by a parallel binding of $n_{e}$ same type rod or pipe electrodes, arranged in line, is determined according to the equation:

$$
\mathrm{R}_{\mathrm{Pe}}=\frac{\mathrm{r}_{\mathrm{p} v}}{\mathrm{u}_{\mathrm{p} \ell} \cdot \mathrm{n}_{\mathrm{e}}}
$$

wherein $r_{p v}$ is the earth electrode resistance (2); $u_{p}$ - the coefficient of use of the combined earthing system, with the electrodes arranged in line, given by the equation:

$$
\mathrm{u}_{\mathrm{p} \ell}=\frac{3-2.5 \beta}{3+2 \beta-7.75 \beta^{2}}
$$

in which the notation $\beta$ represents the ratio:

$$
\beta=\frac{\rho_{\mathrm{p}}}{2 \pi \mathrm{r}_{\mathrm{p} v}} .
$$

From the expressions of the variable $\beta$ and the coefficient of use $u_{p} \ell$, it can be noticed that only in the case of VEGL does the coefficient of use not depend on the number of the electrodes.

The resistance to earth, $\mathrm{R}_{\mathrm{PC}_{\mathrm{C}}}$, owing to the horizontal strip is given by the equation:

$$
\mathrm{R}_{\mathrm{Pc}}=\frac{18.3}{\mathrm{a} \cdot \mathrm{n}_{\mathrm{e}}} \cdot \lg \left(62.5 \cdot \mathrm{a}^{2} \cdot \mathrm{n}_{\mathrm{e}}^{2}\right),
$$

in which the distance between adjacent electrodes is considered known.

The total resistance to earth, $R_{\mathrm{P} \ell}$, of the combined VEGL may be calculated as follows:

$$
\mathrm{R}_{\mathrm{p} \ell}=\frac{\mathrm{R}_{\mathrm{Pe}} \cdot \mathrm{R}_{\mathrm{Pc}}}{\mathrm{R}_{\mathrm{Pe}}+\mathrm{R}_{\mathrm{Pc}}} \leq \mathrm{R}_{\mathrm{Pn}}
$$

verifying as much as possible the fulfillment of the condition in comparison with the design value resistance. In this paper, it is considered that only the artificial VEGL is dimensioned so that a natural earthing system does not exist. 


\subsection{Optimal Criteria}

\subsubsection{The Footprint Area}

In the case of the VEGL, the footprint area, $\mathrm{A}_{\mathrm{pl}}$, (Figure $1 \mathrm{~b}$ ) is:

$$
\mathrm{A}_{\mathrm{p}}=\mathrm{n}_{\mathrm{e}} \cdot \mathrm{a}^{2}, \mathrm{~m}^{2}
$$

where the physical sizes that appear have already been explained.

\subsubsection{The VEGL Total Volume}

The second criterion proposed for the overall characterization of the earthing system refers to the total volume, given by the relation:

$$
\mathrm{V}_{\mathrm{p}}=\mathrm{A}_{\mathrm{p}} \cdot(\ell+\mathrm{q}), \mathrm{m}^{3}
$$

The VEGL total volume combines the characteristics from the horizontal plane, such as the distance between adjacent electrodes, the number, and the arrangement of the electrodes, with the dimensions from the vertical plane, represented by the length of the electrodes $\ell$ and the burial depth q. This criterion can emphasize significant correlations with the criterion of the footprint area.

\subsubsection{The VEGL Dispersion Surface Area}

The VEGL dispersion surface area is considered as the VEGL's total surface in contact with the soil, composed of the sum of the outer areas of the electrodes and of the horizontal strip, according to the relation:

$$
\mathrm{A}_{\mathrm{D}}=\pi \mathrm{d} \ell \mathrm{n}_{\mathrm{e}}+\left(\mathrm{n}_{\mathrm{e}}-1\right) \mathrm{ap} \mathrm{p}_{\mathrm{b}}
$$

in which we find the VEGL characteristic sizes, previously explained (Figure 1), and $\mathrm{p}_{\mathrm{b}}$ is the perimeter of the horizontal strip.

\subsubsection{The VEGL Metal Mass}

The VEGL metal mass constitutes a characteristic size for the VEGL because it combines sizes such as diameter, length, thickness, and electrode number, with the horizontal strip dimensions. The VEGL total metallic mass $M_{P}$, including the pipe's metal mass, as well as the horizontal strip mass, is given by the relation:

$$
\mathrm{M}_{\mathrm{P}}=\gamma_{\mathrm{m}}\left[\pi \mathrm{g}(\mathrm{d}-\mathrm{g}) \ell \mathrm{n}_{\mathrm{e}}+\left(\mathrm{n}_{\mathrm{e}}-1\right) \mathrm{aS}_{\mathrm{b}}\right] .
$$

where $\gamma_{\mathrm{m}}$ is the metal; $\mathrm{g}$-pipe thickness, in $\mathrm{m} ; \mathrm{S}_{\mathrm{b}}$ - the section of the horizontal strip or bar that connects the electrodes, in $\mathrm{m}^{2}$.

\subsubsection{Total Investment}

The calculation relation of the total investment expenses for the VEGL realization has the next relation [11]:

$$
\mathrm{I}_{\mathrm{P}}=\left[\mathrm{c}_{\mathrm{e}}\left(1+\mathrm{m}_{\%}\right) \ell+\mathrm{c}_{\mathrm{b}} \mathrm{a}+\ell \sum_{\mathrm{j}} \mathrm{c}_{\mathrm{hj}} \mathrm{h}_{\mathrm{j}}+\left(\mathrm{c}_{\mathrm{q}}+\mathrm{c}_{\mathrm{a}}\right) \mathrm{a}^{2} \mathrm{q}+\mathrm{c}_{\mathrm{P}} \mathrm{a}^{2}\right] \cdot \mathrm{n}_{\mathrm{e}}, \mathrm{u} . \mathrm{m}_{.},
$$

where $c_{\mathrm{e}}$ represents the cost per unit of length of the electrode, in u.m./m (u.m.-monetary units, which may be lei, Euro, etc.); $\mathrm{m} \%$-the percentage cost of small materials, relative to the cost of the electrodes, in \%; $c_{b}$ 一the cost per unit of length of the horizontal strip, in u.m./m; $\mathrm{c}_{\mathrm{hj}}$ - equivalent value of a working hour, for each of the corresponding trades, in u.m./h; $h_{j}$-number of hours assigned to the corresponding trades, in $\mathrm{h} / \mathrm{m} ; \mathrm{c}_{\mathrm{q}}$ and $\mathrm{c}_{\mathrm{a}}$-the specific costs for uncovering and respectively covering 
the VEGL land, in u.m. $/ \mathrm{m}^{3} ; \mathrm{c}_{\mathrm{P}}$-the equivalent cost of the surface unit for the land on which the VEGL is realized.

The direct proportionality between the investment expenses $I_{P}$ and the number of the electrodes can be observed from (12). In order to make some quantitative assessments, the following values for the calculation sizes from (12) are considered:

- The cost per length unit of the electrode material is dependent on the diameter $d$ and the thickness $\mathrm{g}$ of the pipe wall, as indicated below in the manner adopted in [16]:

$$
\frac{c_{\mathrm{e}}}{\mathrm{d}} \in\left\{\frac{9.18}{0.025} ; \frac{12.22}{0.032} ; \frac{15.72}{0.040} ; \frac{22.84}{0.051} ; \frac{29.71}{0.065}\right\}, \text { u.m. } / \mathrm{m}^{2} .
$$

- The percentage cost $\mathrm{m} \%$ of the small materials were identified based on the norms data as a linear dependence on the electrode length $\ell$, according to the relation:

$$
\mathrm{m}_{\%}=2.78-0.66 \cdot \ell, \% .
$$

- The other costs are estimated as follows:

$$
c_{b}=5.99 \text { u.m. } / \mathrm{ml} ; \sum_{j=1}^{3} c_{h j} h_{j}=19.4 \text { u.m. } / \mathrm{ml} ;\left(c_{q}+c_{a}\right)=15 \text { u.m. } / \mathrm{m}^{2} . c_{P}=15 \text { u.m. } / \mathrm{m}^{2} .
$$

\section{Results}

\subsection{The Data Set}

The following values of the parameter were considered for performing calculations: $d=0.04 \mathrm{~m}$, $\rho_{\mathrm{p}}=100 \Omega \mathrm{m}, \mathrm{q}=0.8 \mathrm{~m}, \mathrm{~g}=4 \mathrm{~mm}$, and $\mathrm{R}_{\mathrm{Pn}}=4 \Omega$. The following set of values was adopted for the electrode lengths, in order to assure a more uniform coverage of the considered range of values (Section 2.1; so the assignment of some subdivisions of the normalized pipe lengths was excluded):

$$
\ell \in\{0.5 ; 0.8 ; 1 ; 1.25 ; 1.5 ; 2 ; 2.5 ; 3 ; 3.5 ; 4\} \mathrm{m} .
$$

For each value of electrode length and each of the number of the electrodes $n_{e} \geq 2$, the minimum value of the distance between adjacent electrodes (in $\mathrm{cm}$ ) is numerically identified (in Excel) in order to obtain the total resistance to earth, $R_{P}$, to a lower value, but as close as possible to $R_{P n}=4 \Omega$. In this way, we obtained the values for the total resistance to earth $R_{P}$ between a minimum one, $R_{P \min }=3.991407 \Omega$ (for $\ell=1.25 \mathrm{~m}, \mathrm{n}_{\mathrm{e}}=7$ and $\mathrm{a}=1.33 \mathrm{~m}$ ), and a maximum one, $\mathrm{R}_{\mathrm{PMax}}=3.999835 \Omega$ (for $\ell=2 \mathrm{~m}, \mathrm{n}_{\mathrm{e}}=4$ and $\mathrm{a}=2.93 \mathrm{~m}$ ). It was considered useful to highlight in Table 1 the values of the two components of the resistance to earth, $R_{P e}$ and $R_{P c}$, without including the resistance to earth $R_{P}$, which is in the domain mentioned above. Next, the calculations were carried out for all the five proposed optimal criteria (Section 2.3). Due to the relatively small values obtained for the distance between adjacent electrodes, $\mathrm{a} \in\{0.52 ; 0.72 ; 0.92\} \mathrm{m}$, for $\mathrm{n}_{\mathrm{e}}=12$ electrodes, the calculations ended with this case. 
Table 1. Calculated data regarding the application of optimal criteria when sizing VEG, with linear electrode placement, for $\rho_{\mathrm{p}}=100 \Omega \mathrm{m}, \mathrm{r}_{\mathrm{pn}}=4 \Omega$.

\begin{tabular}{cccccccccc}
\hline$\ell, \mathbf{m}$ & $\mathbf{n}_{\mathbf{e}}, \mathbf{p c s}$. & $\mathbf{a}, \mathbf{m}$ & $\mathbf{R}_{\mathbf{P e}}, \mathbf{\Omega}$ & $\mathbf{R}_{\mathbf{P c}}, \mathbf{\Omega}$ & $\mathbf{A P}, \mathbf{m}^{\mathbf{2}}$ & $\mathbf{V P}, \mathbf{m}^{\mathbf{3}}$ & $\mathbf{A D}, \mathbf{m}^{\mathbf{2}}$ & $\mathbf{M P}, \mathbf{k g}$ & $\mathbf{I P}, \mathbf{u} . \mathbf{m}$. \\
\hline 0.5 & 2 & 9.16 & 54.35 & 4.32 & 167.81 & 218.15 & 1.74 & $\mathbf{1 4 . 9 6}$ & 9412.99 \\
3 & 2 & 6.98 & 15.75 & 5.36 & 97.44 & 370.28 & 1.98 & 29.88 & 5729.04 \\
0.5 & 3 & 5.82 & 36.71 & 4.49 & 101.62 & 132.10 & 1.72 & 19.82 & 5803.98 \\
0.8 & 3 & 5.50 & 26.14 & 4.69 & 90.75 & 145.20 & 1.75 & 22.20 & 5259.34 \\
0.5 & 4 & 4.16 & 27.92 & 4.66 & 69.22 & 89.99 & 1.72 & 22.63 & 4054.17 \\
0.5 & 6 & 2.51 & 22.67 & 4.86 & 37.80 & 49.14 & 1.70 & 26.25 & 2390.14 \\
2.5 & 6 & 1.03 & 6.64 & 10.00 & 6.37 & 21.01 & 2.43 & 59.36 & 1180.37 \\
0.5 & 7 & 2.05 & 16.71 & 5.24 & 29.42 & 38.24 & 1.70 & 27.70 & 1961.64 \\
0.5 & 8 & 1.70 & 14.87 & 5.47 & 23.12 & 30.06 & 1.70 & 28.97 & 1647.60 \\
1.25 & 9 & 0.47 & 5.56 & 13.19 & 1.99 & 4.08 & 1.79 & 44.39 & 875.53 \\
1.25 & 10 & 0.69 & 7.04 & 9.21 & 4.76 & 9.76 & 2.18 & 51.86 & 1126.34 \\
0.8 & 11 & 0.85 & 8.82 & 7.32 & 7.95 & 12.72 & 1.93 & 41.66 & 1113.71 \\
1 & 11 & 0.72 & 7.68 & 8.30 & 5.70 & 10.26 & 2.08 & 47.80 & 1113.98 \\
0.5 & 12 & 0.93 & 10.63 & 6.38 & 6.22 & 9.95 & 1.97 & 43.76 & 1070.90 \\
0.8 & 12 & 0.72 & 8.22 & 7.77 & 3.24 & 5.84 & 2.06 & 49.48 & 1037.20 \\
\hline
\end{tabular}

The important extension of the data table and the limitation of the paper volume led to the exclusion of some more significant lines mentioned in Table 1, which include, first and foremost, the minimum values and some close to them for each of the five optimal criteria. Before proceeding to a more careful analysis of the data, the ratios between the highest value and the smallest one from each of the applied optimal criteria are considered significant:

- $167.8 / 1.99=84.3$ at the $A_{P}$ criterion;

- $370.3 / 4.08=90.8$ at the $\mathrm{V}_{\mathrm{P}}$ criterion;

- $170 / 16.8=10.1$ at $\mathrm{M}_{\mathrm{P}}$ criterion;

- $6.1 / 1.7=3.59$ at $\mathrm{A}_{\mathrm{D}}$ criterion;

- $9.412 / 875.5=10.8$ at $\mathrm{I}_{\mathrm{P}}$ criterion.

These ratio values show how big the savings regarding land, materials, and cost can be by applying optimal criteria.

\subsection{The Characteristic Curves $a\left(\ell, n_{e}\right)$}

As was in the case of the VEGL [15-17], we first proceed to the graphical representation of the dependence between the distance a and the length of the electrodes $\ell$, having the electrode number as a parameter. Thus, we represented the function $\mathrm{a}\left(\ell, \mathrm{n}_{\mathrm{e}}\right)$, in which the values $\mathrm{n}_{\mathrm{e}} \in\{2,3,4, \ldots, 12\}$ were considered. The obtained curves family is shown in Figure 2. The left limits of each curve correspond to a value given to the number of the electrodes, so $\mathrm{a}\left(\ell_{\min }, \mathrm{n}_{\mathrm{e}}\right)$, for $\mathrm{n}_{\mathrm{e}}-$ constant, corresponds to the minimum value adopted for the length of the electrodes, $\ell_{\min }=0.5 \mathrm{~m}$.

The upper limits $\ell_{\text {Max }}$ of the independent variable $\ell$, are $\ell_{\text {Max }}=4 \mathrm{~m}$, for $n_{e} \in\{2 ; 3 ; 4\}$. For greater numbers of electrodes, $\mathrm{n}_{\mathrm{e}} \in\{5 ; 6 ; 7, \ldots, 12\}$, different values of $\ell_{\text {Max }}$ are obtained from one curve to another, corresponding to the limit of applicability of the mathematical model (the anomalies appear in the values monotony for the distance between adjacent electrodes in the ranges of its smaller values). The continuity and monotony of the graphs indicate a good accuracy in the numerical determination of the distance between adjacent electrodes from the mathematical model of this VEGL type.

Based on these graphs (Figure 2), it is possible to determine the distance between adjacent electrodes for any other electrodes lengths $\ell \in[0.5-4] \mathrm{m}$, to achieve the design value resistance $\mathrm{R}_{\mathrm{Pn}}=4 \Omega$, when $\rho_{\mathrm{p}}=100 \Omega \mathrm{m}$ and the other parameters have the previously set values. 


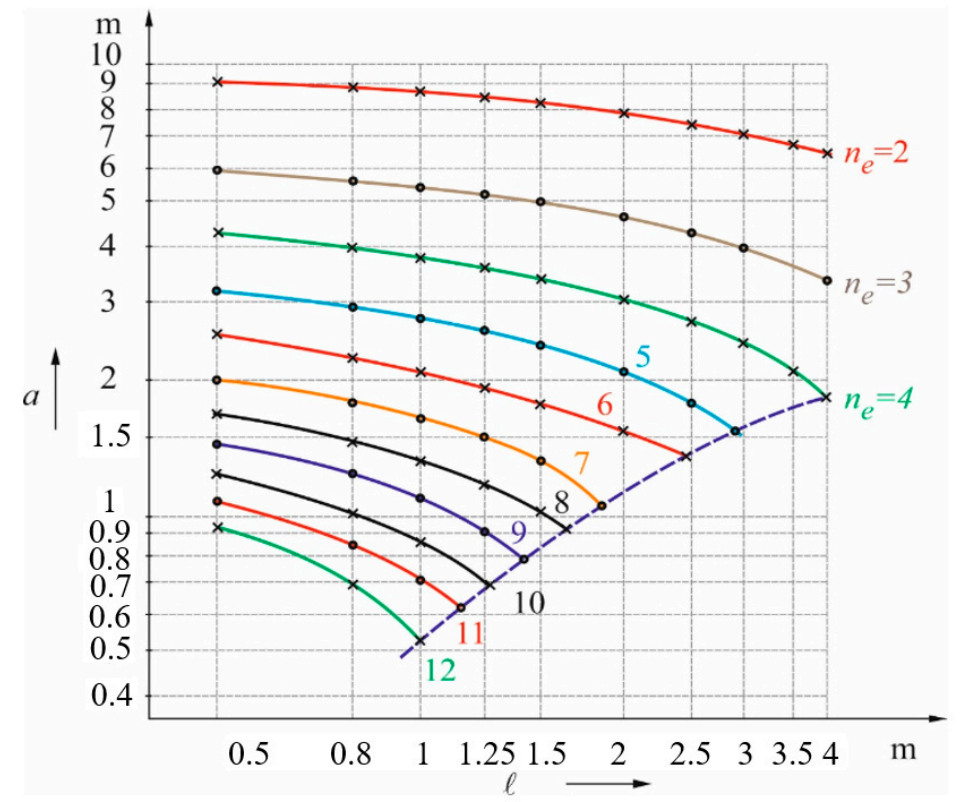

Figure 2. The graph of the function a $\left(\ell\right.$, ne), having as parameter the number of the electrodes $n_{e}$, for $\rho_{\mathrm{p}}=100 \Omega \mathrm{m}$ and $\mathrm{R}_{\mathrm{Pn}}=4 \Omega$.

At the end of these considerations relative to the $\mathrm{a}\left(\ell, \mathrm{n}_{\mathrm{e}}\right)$ curves, with $\mathrm{n}_{\mathrm{e}}$ as a parameter and for which the name of EG characteristic curves is considered adequate, it is useful to make a comparison with the similar curves from the case of VEGR, presented in [16]. As a general appreciation, the distance between adjacent electrodes is greater in the case of VEGL than in the case of VEGR in order to obtain the same total resistance to earth $R_{P}$. Thus, considering the case of $n_{e}=4$, for $\ell=0.8 \mathrm{~m}$, the distance between adjacent electrodes must be $\mathrm{a}=4 \mathrm{~m}$ at VEGL, compared to $\mathrm{a}=3.8 \mathrm{~m}$ in the case of arrangement in rectangle (difference of about $5 \%$ ). If $\ell=4 \mathrm{~m}$, the distance between adjacent electrodes must be $\mathrm{a}=1.8 \mathrm{~m}$ at VEGL, while $\mathrm{a}=1 \mathrm{~m}$ in the case of VEGR (difference of about $44 \%$ ).

\subsection{Minimum Zones}

The minimum zones, corresponding to the optimum criteria for VEGL, are represented in the $(\ell$, a) plane, based on the data from Table 1 . Thus, for each criterion, at least three of the minimum values where held, to which from one to three points with very close values were associated. The graph with the minimum zones is shown in Figure 3, where the minimum areas, corresponding to each optimal criterion, are identified by the notations introduced in their analytical definition: $A_{P}-$ for the footprint area, $V_{P}$ - for the VEGL total volume, $A_{D}$ - for the VEGL dispersion surface area, $M_{P}$-for the metallic materials mass, and $\mathrm{I}_{\mathrm{P}}$-for the VEGL total investment cost.

In order to simplify the identification of different solutions from Table 1 , to which some points from Figure 3 are corresponding, it is proposed to identify the solution through the set of sizes $\left(\ell ; n_{\mathrm{e}}\right.$; a), in this order. Thus, the solution representing the absolute minimum at the criterion of the footprint area, $A_{P}=1.99 \mathrm{~m}^{2}$ (Table 1 ), has the coordinates $(1.25 ; 9 ; 0.47)$. In the figure, the position of the absolute minimum, according to a specific criterion, is indicated by an arrow (Figure 3 ).

As a general aspect, it can be observed that there is a bipolarization of the minimum areas, corresponding to the five optimal criteria: one at the small electrode lengths, $\ell \in\{0.5 ; 0.8\} \mathrm{m}$, where the minimum areas for $A_{D}$ and $M_{P}$ criteria are positioned and the other at the smaller electrode distances, $\mathrm{a} \in[0.47-1.0] \mathrm{m}$, where the minimum areas for the $A_{P}, V_{P}$, and $I_{P}$ criteria are positioned. In this latter situation, the common area of these three minimum zones, which is precisely represented by the $V_{P \min }$ area, defines a three-criteria minimum area. In addition, it should be noted that the solution $(1.25 ; 9$; $0.47)$ represents the absolute minimum for all these three minimum criteria, i.e., $A_{P}, V_{P}$, and $I_{P}$. 


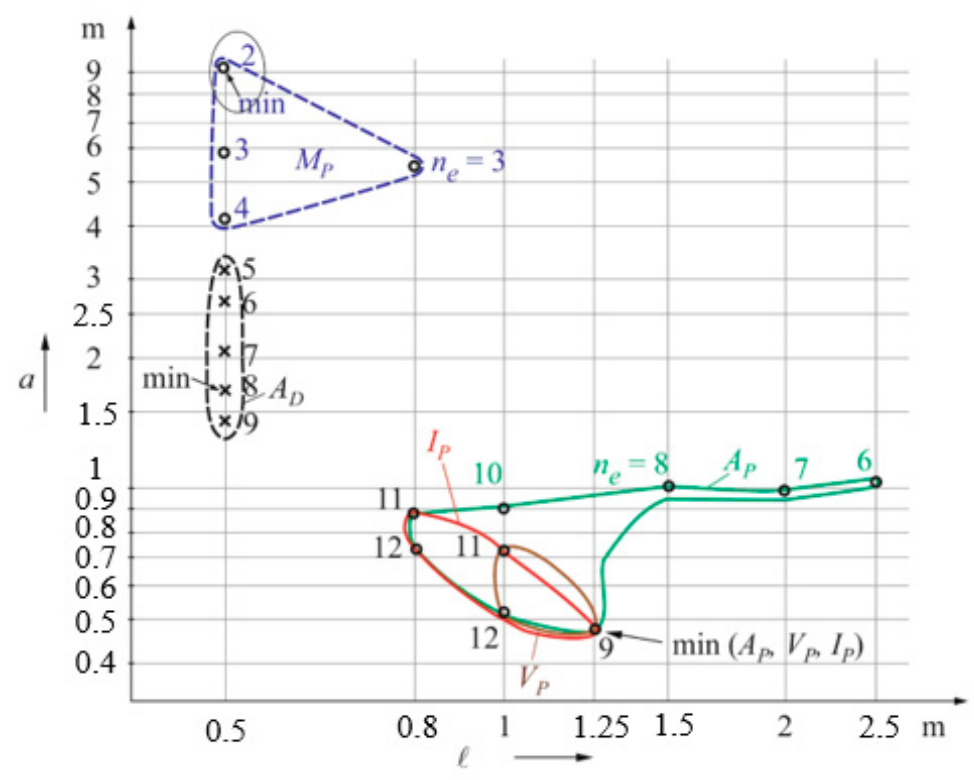

Figure 3. The minimum areas corresponding to the optimal criteria in the $(\ell$, a) plane, for VEGL.

Regarding the minimum areas for the $A_{D}$ and $M_{P}$ criteria, even if they are located at the same abscissa from the lower limit of the range of the electrode length values, they are disjointed. The absolute minimum, according to $\mathrm{A}_{\mathrm{D}}$ criterion, corresponds to the solution $(0.5 ; 8 ; 1.70)$, while the one according to the $\mathrm{M}_{\mathrm{P}}$ criterion corresponds to the solution $(0.5 ; 2 ; 9.16)$. The latter appears as an extreme case, with only two electrodes of small length, $\ell=0.5 \mathrm{~m}$, located at considerable distances, a $=9.16 \mathrm{~m}$, so over 18 times the length of the electrodes. This case reveals a question regarding the validity ranges of mathematical models proposed for the dimensioning of different types and configurations of EG.

By increasing the number of solutions included in the minimum areas, which means increasing the admitted deviation from the absolute minimum recorded in the $A_{D}$ and $M_{P}$ criteria, the two corresponding minimum areas generate an intersection, resulting in a bicriteria minimum area.

The use of logarithmic scales for both variables, $\ell$ and $a$, allowed a better highlighting of the minimum areas according to the $A_{P}, V_{P}$, and $I_{P}$ criteria, located in the range of smaller values of the distance between adjacent electrodes, $\mathrm{a} \in[0.4-1] \mathrm{m}$.

Finally, trying a comparison of the location of the minimum areas between the case of VEGL [12], it can be noticed a similar relative location of the minimum areas, even if the average coordinate values are different. Secondly, there is a significant reduction of the value ranges corresponding to the minimum areas according to the $(0 \ell)$ axis. Thus, the minimum area according to the $A_{P}$ criterion is extended over the interval $\ell \in[0.8-2.5] \mathrm{m}$ (Figure 3) at VEGL, while at VEGR $\ell \in[0.8-4.0] \mathrm{m}$ [12].

\section{Discussion}

VEGL sizing by applying optimal criteria offers the benefits of a simpler expression for the coefficient of use (4) and the fact that the number of the electrodes can be any natural number, compared to VEGL addressed in [15-17].

The calculation methodology, developed in relation to VEGR was adapted and applied in the same way to VEGL, for the electrode numbers corresponding to the range $n_{e} \in\{2,3,4, \ldots, 12\}$, and the following values were adopted for the main parameters: $d=0.04 \mathrm{~m}, \rho_{\mathrm{p}}=100 \Omega \mathrm{m}, \mathrm{q}=0.8 \mathrm{~m}$, and $\mathrm{R}_{\mathrm{Pn}}=4 \Omega$. The specificity of the calculation methodology consists of the preliminary calculation of the resistance to earth of one electrode $r_{p v}(2)$, for each of the combinations: electrode length-electrode number-distance between adjacent electrodes.

The range for the electrode length comprised 10 values (15), and the number of electrodes corresponded to 11 consecutive values (as mentioned above) so that the matrix with the total number 
of technically appropriate solutions is 110 . Therefore, the optimal solution of each optimal criterion was identified among 110 technically appropriate solutions.

It would be expected that the optimal solutions are located at substantially equal values of the resistances to earth of all electrodes, and for the horizontal strip, that is for $\mathrm{R}_{\mathrm{Pe}}=\mathrm{R}_{\mathrm{Pc}} \approx 8 \Omega$. However, the absolute minimum solution, for three criteria $\left(A_{P}, V_{P}\right.$, and $\left.I_{P}\right)$, having the coordinates $(1.25 ; 9 ; 0.47)$, occurs in the conditions in which the two components of the total resistance to earth are very different, $\mathrm{R}_{\mathrm{Pe}}=5.56 \Omega$ and $\mathrm{R}_{\mathrm{Pc}}=13.19 \Omega$. The hypothesis stated above is fulfilled for the solution $(3.5 ; 4 ; 2.11)$, when the values $R_{\mathrm{Pe}}=8.09 \Omega$ and $\mathrm{R}_{\mathrm{Pc}}=7.91 \Omega$ are recorded, but this variant does not fit into the five criteria optimal areas. In contrast, the solution $(0.8 ; 12 ; 0.72)$, for which $R_{P e}=8.22 \Omega$ and $R_{P c}=7.77 \Omega$, is part of the minimum bicriteria area, $A_{P}$ and $I_{P}$.

Graphs, such as a $\left(\ell, \mathrm{n}_{\mathrm{e}}\right)$ (Figure 2), make it possible to directly determine the distance between adjacent electrodes, for any electrode lengths.

Regarding the minimum areas, the essential aspect highlighted by the present research is their polarization. At one side is a three criteria minimum area, according to the $A_{P}, V_{P}$, and $I_{P}$ criteria, where the absolute minimum solution is located at the coordinates $\ell=1.25 \mathrm{~m}, \mathrm{n}_{\mathrm{e}}=9$, and $\mathrm{a}=2.11 \mathrm{~m}$. On the other side, at the lower values of the length of the electrodes, $\ell \in[0.5-0.8] \mathrm{m}$, the minimum areas corresponding to the other two criteria, $\mathrm{A}_{\mathrm{D}}$ and $\mathrm{M}_{\mathrm{P}}$, are in the vicinity.

Comparing a solution proposed as "a good practice" [6], having the data $\ell=3 \mathrm{~m}, \mathrm{n}_{\mathrm{e}}=5, \mathrm{a}=6 \mathrm{~m}$, and the other sizes identical to those considered when calculating the data in Table 1, we can find the followings: it occupies an area 90.5 times greater than the minimum, has a volume of 167.6 times larger, uses 4.9 times more metal, and costs 12.3 times more than the minimum variants, corresponding to the respective criteria.

Author Contributions: Conceptualization, S.G.P. and V.M.; methodology, V.M. and H.G.B.; validation, S.G.P., V.M., and C.C.; formal analysis, H.G.B. and I.B.; writing—original draft preparation, S.G.P. and V.M.; writing—review and editing, C.C. and I.B.; visualization, S.G.P. and H.G.B.; supervision, V.M. All authors have read and agreed to the published version of the manuscript.

Funding: This research received no external funding.

Acknowledgments: The results presented in this paper were obtained in the framework of the GNaC 2018 ARUT grant "Consequences of Power Quality Issues for Electromechanical Receivers", research Contract no. 3092/05.02.2019, with the financial support of the Technical University of Cluj-Napoca.

Conflicts of Interest: The authors declare no conflict of interest.

\section{References}

1. BS Code of Practice for Earthing; BS 7430; BS: Geneva, Switzerland, 1998.

2. BS (IEC). Glossary of Electrotechnical, Power, Telecommunication, Electronics, Lighting and Color Terms; BS 4727-1: Group 09:1991 (IEC 60050-161:1990); BS: Geneva, Switzerland, 1990.

3. IEC. Low-Voltage Electrical Installations-Selection and Erection of Electrical Equipment-Earthing Arrangements and Protective Conductors; IEC 60364-5-54:2011; IEC: Geneva, Switzerland, 2011.

4. IEC. Earthing of Power Installations Exceeding 1 kV a.c.; IEC EN Standard 50522/Jul. 2011; IEC: Brussels, Belgium, 2011.

5. Normative for the Design, Execution and Operation of Electrical Installations Related to Buildings, I7-2011; MATRIX ROM: Bucharest, Romania, 2011; Volume 1-2.

6. Good Practice Guide for Designing Lighting/Protection Installations in Buildings; Gex 12-2015; MATRIX ROM: Bucharest, Romania, 2016.

7. Sufrim, M. Design and Construction Guide for Earthing Systems; 1 RE-Ip 30/2004; SIER Ed.: Bucharest, Romania, 2004.

8. STAS. Electrical Installations of 1,000 V and More than 1,000 V. Installations for Protective Earthing; STAS 7334-83; ASRO: Bucharest, Romania, 1983.

9. Comşa, D.; Darie, S.; Maier, V.; Chindriş, M. Design of the Industrial Electrical Installations, 2nd ed.; Editura Didactică şi Pedagogică: Bucharest, Romania, 1983. 
10. Lucache, D.D. Low-voltage Electrical Installations, Theoretical Basics and Designing Elements; Editura PIM: Iași, Romania, 2009.

11. Markievicz, H.; Klajn, A. Earthing and EMC, Earthing Systems-Basical Constructive Aspects, Application Guide-Power Quality; SIER Ed.: Bucharest, Romania, 2004.

12. Seidman, A.; Beaty, H.W.; Mahrous, H. Handbook of Electric Power Calculations, 2nd ed.; McGraw-Hill: New York, NY, USA, 1996.

13. Sufrim, M.; Goia, M.L.; și Petran, M. Earthing Installations; Editura Tehnică: Bucharest, Romania, 1987.

14. Maier, V.; Pavel, S.G.; Beleiu, H.G.; Birou, I.; Fărcaș, V. Nomograms for sizing the vertical earth grounding. In Proceedings of the EPE, Bucharest, Romania, 20-22 October 2016; pp. 483-486.

15. Maier, V.; Pavel, S.G.; Beleiu, H.G.; Pică, C.S. Vertical Earth Grounding Design Using Optimal Criteria. In Proceedings of the ATEE, Bucharest, Romania, 23-25 March 2017; pp. 539-544.

16. Ciorca, C.; Maier, V.; Pavel, S.G.; Birou, I.; Beleiu, H.G. Dimensioning of the Vertical Earth Grounding with Rectangular Contour through Minimizing the Investments Costs. In Proceedings of the EPE 2018, Bucharest, Romania, 17-21 September 2018; pp. 154-158.

17. Maier, V.; Pavel, S.G.; Ciorca, C.; Birou, I.; Beleiu, H.G. Dissipation Surface Minimization of Vertical Earth Grounding, with Rectangular Contour. In Proceedings of the ATEE, Bath, UK, 14-16 August 2019.

18. He, J.; Gao, Y.; Zeng, R.; Sun, W.; Zou, J.; Guan, Z. Optimal Design of Grounding System Considering the Influence of Seasonal Frozen Soil Layer. IEEE Trans. Power Deliv. 2005, 20, 107-115.

19. Wang, S. Optimal Arrangement of Long Vertical Rods to Reduce Ground Resistance considering Their Shielding Effect. In Proceedings of the IEEE ICHVE 2018, Athens, Greece, 10-13 September 2018.

(C) 2020 by the authors. Licensee MDPI, Basel, Switzerland. This article is an open access article distributed under the terms and conditions of the Creative Commons Attribution (CC BY) license (http://creativecommons.org/licenses/by/4.0/). 